\title{
Contractile mitral annular forces are reduced with ischemic mitral regurgitation
}

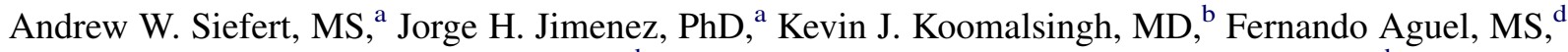 \\ Dustin S. West, BS, ${ }^{\mathrm{a}}$ Takashi Shuto, MD, ${ }^{\mathrm{b}}$ Teresa K. Snow, PhD, ${ }^{\mathrm{c}}$ Robert C. Gorman, MD, ${ }^{\mathrm{b}}$ \\ Joseph H. Gorman III, MD, ${ }^{b}$ and Ajit P. Yoganathan, $\mathrm{PhD}^{\mathrm{a}}$
}

\begin{abstract}
Objective: Forces acting on mitral annular devices in the setting of ischemic mitral regurgitation are currently unknown. The aim of this study was to quantify the cyclic forces that result from mitral annular contraction in a chronic ischemic mitral regurgitation ovine model and compare them with forces measured previously in healthy animals.
\end{abstract}

\begin{abstract}
Methods: A novel force transducer was implanted in the mitral annulus of 6 ovine subjects 8 weeks after an inferior left ventricle infarction that produced progressive, severe chronic ischemic mitral regurgitation. Septal-lateral and transverse forces were measured continuously for cardiac cycles reaching a peak left ventricular pressure of 90, 125, 150, 175, and $200 \mathrm{~mm} \mathrm{Hg}$. Cyclic forces and their rate of change during isovolumetric contraction were quantified and compared with those measured in healthy animals.
\end{abstract}

\begin{abstract}
Results: Animals with chronic ischemic mitral regurgitation exhibited a mean mitral regurgitation grade of 2.3 \pm 0.5 . Ischemic mitral regurgitation was observed to decrease significantly septal-lateral forces at each level of left ventricular pressure $(P<.01)$. Transverse forces were consistently lower in the ischemic mitral regurgitation group despite not reaching statistical significance. The rate of change of these forces during isovolumetric contraction was found to increase significantly with peak left ventricular pressure $(P<.005)$, but did not differ significantly between animal groups.
\end{abstract}

Conclusions: Mitral annular forces were measured for the first time in a chronic ischemic mitral regurgitation animal model. Our findings demonstrated an inferior left ventricular infarct to decrease significantly cyclic septal-lateral forces while modestly lowering those in the transverse. The measurement of these forces and their variation with left ventricular pressure contributes significantly to the development of mitral annular ischemic mitral regurgitation devices. (J Thorac Cardiovasc Surg 2013;146:422-8)

During the past decade, the surgical correction of ischemic mitral regurgitation (IMR) has relied on undersized mitral annuloplasty and mitral valve replacement. ${ }^{1-3}$ Their use, however, has been challenged by the growing number of patients who are elderly or who present with significant comorbidities deemed too high risk for these procedures. ${ }^{4-7}$ This trend, paired with an increasing desire for less invasive approaches, has led to the development

From The Wallace H. Coulter Department of Biomedical Engineering, ${ }^{a}$ Georgia Institute of Technology and Emory University, Atlanta, Ga; the Gorman Cardiovascular Research Group, ${ }^{\mathrm{b}}$ University of Pennsylvania, Glenolden, Pa; the School of Applied Physiology, ${ }^{\mathrm{c}}$ Georgia Institute of Technology, Atlanta, Ga; and the Division of Cardiovascular Devices, ${ }^{\mathrm{d}}$ Food and Drug Administration, Silver Spring, Md.

This study was supported by a research grant awarded from the Food and Drug Administration (FDA1061718) and by grants from the National Heart, Lung and Blood Institute of the National Institutes of Health, Bethesda, Md. (HL63954 and HL73021). Dr Gorman and Dr Gorman were supported by individual Established Investigator Awards from the American Heart Association, Dallas, Tex.

Disclosures: Authors have nothing to disclose with regard to commercial support.

Received for publication Aug 16, 2012; revisions received Sept 14, 2012; accepted for publication Oct 2, 2012; available ahead of print Oct 29, 2012.

Address for reprints: Ajit P. Yoganathan, PhD, 313 Ferst Drive, Atlanta, GA 30332

(E-mail: ajit.yoganathan@bme.gatech.edu).

0022-5223/ $\$ 36.00$

Copyright (c) 2013 by The American Association for Thoracic Surgery

http://dx.doi.org/10.1016/j.jtcvs.2012.10.006 of minimally invasive and percutaneous surgery for IMR. Although these techniques exhibit potential for treating a large number of patients, many challenges remain in demonstrating equivalent or improved clinical therapeutic benefits compared with optimally performed mitral annuloplasty or valve replacement. ${ }^{6-8}$

A key to demonstrating equivalent or improved clinical therapeutic benefits is the development of minimally invasive devices that not only facilitate delivery but reduce IMR. Although reductions in mitral regurgitation (MR) have been shown in preclinical studies, concerns have been raised regarding the safety of these devices. ${ }^{5-9}$ In specific, these devices are structurally smaller, more flexible, and may be less durable than comparably rigid replacement valves or rigid undersized complete annuloplasty rings. As a result, these devices may experience greater structural deformations and as such may be more prone to strain-related material failure. ${ }^{5,7,9}$

Despite their fundamental importance, limited knowledge exists regarding the forces acting on devices implanted in the mitral annulus. ${ }^{10-13}$ Isolated directions of compressive force on mechanical and prosthetic mitral valves have been measured and found to range from 6 to $8 \mathrm{~N}$ and from 4.4 to $13.9 \mathrm{~N}$, respectively. ${ }^{10,11}$ Although of 


\section{Abbreviations and Acronyms \\ $\mathrm{dF} / \mathrm{dt}=$ peak rate of change of force \\ $\mathrm{d}(\mathrm{LVP}) / \mathrm{dt}=$ peak rate of change of LVP \\ IMR $=$ ischemic mitral regurgitation \\ $\mathrm{LV} \quad=$ left ventricular \\ LVP $=$ left ventricular pressure \\ $\mathrm{MR} \quad=$ mitral regurgitation}

lesser magnitude, additional studies have revealed the influence of a saddled geometry on the distribution of bending forces in simulated annuloplasty rings. ${ }^{12,13}$ Although groundbreaking, each of these studies was limited to a healthy porcine model and was unable to quantify the effects of ventricular or valvular disease on measured forces. The directional variation and rate of change of these forces for increasing ventricular afterload are also unavailable.

Determining these unknowns are critical to the design and evaluation of minimally invasive and transcatheter devices. Because many of these devices are heterogeneous directionally, evaluating directional differences in force with increasing ventricular afterload can inform worst-case loading conditions. Determining the rate of change of these forces during ventricular contraction will also inform device testing and the use of device materials with rate- or time-dependent material properties. The ability to quantify these end points in the presence of an inferior left ventricular infarction will contribute significantly to the development of minimally invasive and percutaneous IMR devices. To this end, we now describe the use of a novel force transducer to measure the septal-lateral and transverse forces that result from mitral annular contraction in a chronic IMR ovine model at increasing levels of ventricular afterload.

\section{METHODS}

\section{Mitral Annular Force Transducer}

A novel transducer was developed to measure in-plane radial forces resulting from mitral annular contraction. ${ }^{14,15}$ Pictured in Figure 1, this device has a D-shaped profile with a size that is constrained to mitral annular dimensions measured previously in an identical chronic IMR model. ${ }^{16}$ The transducer included 2 measurement arms oriented in the septal-lateral and transverse directions of the mitral annulus. To facilitate implantation, each measurement arm included lateral passages to secure sutures between the annulus and the device. The development, fabrication, calibration, accuracy, sensitivity, and use for the measurement of annular forces in healthy ovine animals have been reported previously. ${ }^{14,15}$

\section{Chronic IMR Animal Model}

The animals used in this work received care in compliance with the protocols approved by the Institutional Animal Care and Use Committee at the University of Pennsylvania in accordance with the guidelines for humane care. ${ }^{17}$ Six ovine subjects received an inferior left ventricular infarction to produce progressive, chronic IMR. This model has been studied extensively and mimics precisely an inferior infarction described in humans. ${ }^{16,18-20}$ Through a sterile left lateral thoracotomy, snares were placed to occlude permanently the proximal second and third obtuse marginal branches of the circumflex coronary artery. After infarction, the thoracotomy was closed and IMR allowed to progress for an 8-week period prior to transducer implantation and annular force measurement.

\section{Experimental Protocol}

Six Dorsett Hybrid sheep $(40.1 \pm 2.9 \mathrm{~kg})$ were intubated, anesthetized, and ventilated with isoflurane $(1.5 \%-2 \%)$ and oxygen. Surface electrocardiogram and arterial blood pressure were monitored. A right thoracotomy was performed. On the heart's exposure, epicardial Doppler echocardiographic images were obtained to evaluate MR at a peak left ventricular pressure (LVP) of approximately $90 \mathrm{~mm} \mathrm{Hg}$ (Phillips IE33 Matrix; Phillips, Amsterdam, The Netherlands). Mitral regurgitation was graded on a $0-$ to $4+$-scale, where 0 represents no MR and 4+ represents severe MR with reversal of pulmonary vein flow. After establishment of cardiopulmonary bypass, a left atriotomy was performed. Eight 2-0 Ethibond Exel polyester sutures (Ethicon, Piscataway, NJ) were passed through the mitral annulus in positions relative to the lateral passages located on the annular force transducer. These sutures were passed through the device and secured to the mitral annulus as in mitral annuloplasty. ${ }^{14,15}$

Visual inspection was used to verify transducer placement and orientation in the mitral annulus. After separation from cardiopulmonary bypass, a high-fidelity pressure transducer (SPR-3505; Millar Instruments, Houston, Tex) was passed percutaneously into the left ventricle through the femoral artery for continuous measurement of LVP. Surface electrocardiogram, LVP, and arterial pressure (Hewlett-Packard 78534C monitor; HewlettPackard, Inc, Santa Clara, Calif) were monitored continuously. On establishing baseline hemodynamics $(90 \mathrm{~mm} \mathrm{Hg}$ peak LVP, $3.3 \mathrm{~L} /$ min cardiac output), forces resulting from mitral annular contraction were measured in the postcardioplegic heart.

To simulate worst-case loading scenarios, forces were recorded throughout the cardiac cycle for increasing levels of peak LVP at 125, 150,175 , and $200 \mathrm{~mm} \mathrm{Hg}$. Elevated levels of LVP were achieved via intravenous injection of norepinephrine. After successful force measurement, animals were euthanized with $1 \mathrm{~g}$ thiopental and $80 \mathrm{mEq} \mathrm{KCl}$. Hearts were removed and opened to verify secure anchoring of the device to the mitral annulus and to measure the total infarct area with respect to the left ventricular (LV) endocardium. This protocol was identical to that used previously to measure mitral annular forces in healthy ovine subjects. ${ }^{15}$

\section{Data Acquisition}

Mitral annular forces were acquired continuously using a compact Data Acquisition System (cDAQ 9174) and a strain gauge bridge module (NI 9237; National Instruments, Austin, Tex). Left ventricular pressure was measured from the Millar pressure catheter's control unit using an analog voltage module (NI 9215; National Instruments). Forces and LVP were monitored and recorded continuously using a customized LabVIEW program (National Instruments) at $1613 \mathrm{~Hz}$. This rate was sufficient for force measurement as well as for the determination of the rate increase of force during isovolumetric contraction. ${ }^{14,15}$

\section{Data and Statistical Analysis}

All acquired data were processed offline using a custom Matlab program (Mathworks, Natick, Mass). Forces are reported as the change from their minimum diastolic value to maximum systolic value. The peak rate of change of LVP (d(LVP)/dt) and force $(\mathrm{dF} / \mathrm{dt})$ with time during isovolumetric contraction were also determined. Peak values measured in each animal were averaged over 10 consecutive cardiac cycles and averaged subsequently in each animal group and level of afterload. All results are reported as a mean \pm 1 standard deviation. 


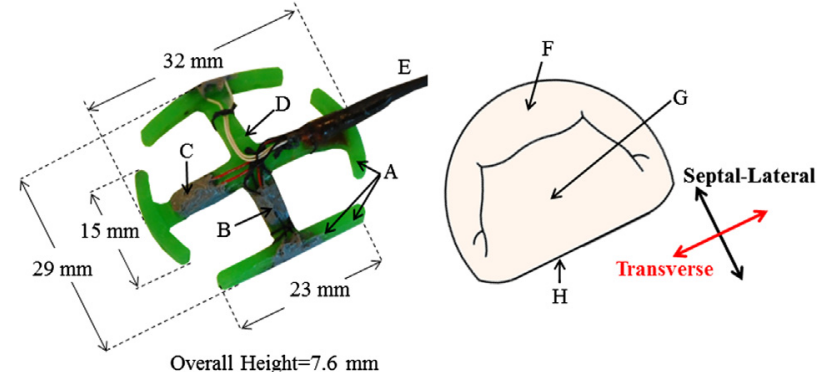

FIGURE 1. Developed mitral annular force transducer with measurement directions and features identified. (A) One-millimeter-diameter suture passages placed in 4-mm increments from the centerline of each measurement arm for transducer-annulus anchoring. (B) Strain gauge to measure septallateral force. $(C)$ Strain gauge to measure transverse force. $(D)$ Transducer spring element. $(E)$ Exit wire harness. $(F)$ Posterior mitral leaflet. $(G)$ Anterior mitral leaflet. $(H)$ Mitral annulus.

Forces measured in the chronic IMR model were compared quantitatively with those measured and reported previously in a healthy ovine model. ${ }^{15}$ Mean measured forces and rates of force with time were checked for normality using the Anderson-Darling test. Changes in force and $\mathrm{dF} / \mathrm{dt}$ with increasing levels of afterload in both the control and chronic IMR group were tested using repeated-measures analysis of variance. If a significant effect was revealed, a Dunnett post hoc test was used to determine whether forces measured at elevated levels of LVP were greater statistically than those measured at baseline conditions. To determine whether differences in force and $\mathrm{dF} / \mathrm{dt}$ exist between each group, between-groups repeated-measures analysis of variance was conducted. If a significant difference was revealed, a conservative Bonferroni post hoc test was used to determine at which levels of ventricular afterload the differences exist. All statistical tests were completed using Minitab 16 (Minitab, Inc, State College, Pa).

\section{RESULTS}

Baseline and Elevated Animal Characteristics

Baseline characteristics of the chronic IMR $(n=6)$ and control $(n=6)$ animals are presented in Table $1 .{ }^{15}$ For the chronic IMR animals, the mean MR grade measured 8 weeks after myocardial infarction was $2.3 \pm 0.5$. Resulting MR grades were comparable with those achieved in previous studies using an identical chronic IMR model. ${ }^{16,18,19}$ When simulating worst-case loading conditions, LVP was controlled carefully in each animal. No statistical differences were observed between animal groups for measured levels of elevated LVP and heart rate (Table 2). During

TABLE 1. Baseline characteristics of the ovine subjects

\begin{tabular}{lcc}
\hline \multicolumn{1}{c}{ Parameter } & $\begin{array}{c}\text { Control animals } \\
(\mathbf{n}=\mathbf{6})\end{array}$ & $\begin{array}{c}\text { Chronic IMR animals } \\
(\mathbf{n}=\mathbf{6})\end{array}$ \\
\hline Weight, $\mathrm{kg}$ & $40.1 \pm 7.4$ & $39.7 \pm 2.6$ \\
Heart rate, beats/min & $95 \pm 15$ & $96 \pm 9$ \\
$\mathrm{LVP}, \mathrm{mm} \mathrm{Hg}$ & $90 \pm 2$ & $92 \pm 2$ \\
$\mathrm{~d}(\mathrm{LVP}) / \mathrm{dt}, \mathrm{mm} \mathrm{Hg} / \mathrm{sec}$ & $2105 \pm 712$ & $1253 \pm 307$ \\
Graded MR & 0 & $2.3 \pm 0.5$ \\
Infarcted endocardium, \% & 0 & $19.0 \pm 1.7$ \\
\hline$I M R$, Ischemic mitral regurgitation; $L V P$, left ventricular pressure; $d(L V P) / d t$, peak \\
rate of change of LVP; $M R$, mitral regurgitation.
\end{tabular}

TABLE 2. Characteristics of the ovine subjects at elevated levels of left ventricular pressure

\begin{tabular}{lccccc}
\hline \multirow{2}{*}{$\begin{array}{c}\text { Parameter and } \\
\text { animal group }\end{array}$} & \multicolumn{6}{c}{ Target peak left ventricular pressure, $\mathbf{~ m m ~ H g}$} \\
\cline { 2 - 7 } & $\mathbf{9 0}$ & $\mathbf{1 2 5}$ & $\mathbf{1 5 0}$ & $\mathbf{1 7 5}$ & $\mathbf{2 0 0}$ \\
\hline $\begin{array}{c}\text { Peak left ventricular } \\
\quad \text { pressure, mm Hg }\end{array}$ & & & & & \\
$\quad$ Control & $90 \pm 2$ & $128 \pm 3$ & $151 \pm 3$ & $173 \pm 3$ & $201 \pm 4$ \\
$\quad$ Chronic IMR & $92 \pm 2$ & $124 \pm 2$ & $152 \pm 2$ & $177 \pm 2$ & $198 \pm 4$ \\
Heart rate, beats/min & & & & & \\
Control & $95 \pm 15$ & $116 \pm 33$ & $127 \pm 32$ & $140 \pm 38$ & $142 \pm 35$ \\
Chronic IMR & $96 \pm 9$ & $111 \pm 11$ & $117 \pm 16$ & $130 \pm 22$ & $143 \pm 18$ \\
\hline IMR, Ischemic mitral regurgitation. & & & &
\end{tabular}

each study, real-time 3-dimensional echocardiographic images were acquired to assess transducer anchoring throughout the experiment. During all experiments, the transducer remained secured firmly to the mitral annulus.

\section{Change in Force Throughout the Cardiac Cycle}

Among control and chronic IMR animals, forces in the septal-lateral and transverse directions were observed to increase compressively from ventricular diastole to mid systole. Representative unfiltered forces from both a control and chronic IMR animal are plotted with time and LVP in Figure 2. In both animals, slight elevations in force are seen during atrial systole followed by sharp increases during isovolumetric contraction. During this period, septallateral and transverse forces were found to increase with LVP $(P<.001)$ and peak at approximately mid systole.

\section{Change in Force With Increasing Afterload: Chronic IMR Animals}

Septal-lateral force in the chronic IMR animals was found to differ statistically between increasing levels of

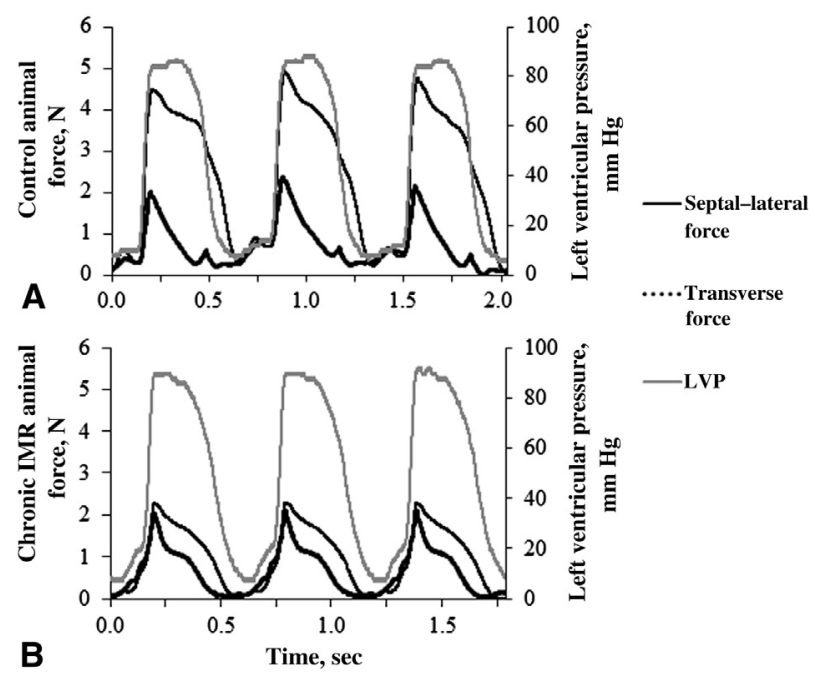

FIGURE 2. Representative unfiltered forces from both a control animal (A) and chronic IMR animal (B) are plotted with time and left ventricular pressure. IMR, Ischemic mitral regurgitation. 
afterload $(P<.001)$. These forces were observed to increase from the baseline of $2.5 \pm 0.6 \mathrm{~N}$ to $3.5 \pm 0.7 \mathrm{~N}$ at $150 \mathrm{~mm}$ $\mathrm{Hg}(P<.001), 3.7 \pm 0.6 \mathrm{~N}$ at $175 \mathrm{~mm} \mathrm{Hg}(P<.001)$, and 3.7 $\pm 0.8 \mathrm{~N}$ at $200 \mathrm{~mm} \mathrm{Hg}(P<.001)$. No significant differences were found between the baseline and $2.9 \pm 0.6 \mathrm{~N}$ at $125 \mathrm{~mm}$ $\mathrm{Hg}$ peak LVP. The peak septal-lateral force measured among all chronic IMR animals was $4.5 \mathrm{~N}$ at $200 \mathrm{~mm} \mathrm{Hg}$ peak LVP.

The change in transverse forces throughout the cardiac cycle were also found to differ statistically with afterload $(P<.05)$. Transverse forces were observed to increase from the baseline of $2.2 \pm 0.9 \mathrm{~N}$ to $2.9 \pm 0.9 \mathrm{~N}$ at 150 $\mathrm{mm} \mathrm{Hg}(P<.05)$ and $2.9 \pm 1.2 \mathrm{~N}$ at $175 \mathrm{~mm} \mathrm{Hg}(P<$ $.05)$. Transverse forces measured at $125 \mathrm{~mm} \mathrm{Hg}(2.7 \pm$ $0.8 \mathrm{~N})$ and $200 \mathrm{~mm} \mathrm{Hg}(2.7 \pm 1.2 \mathrm{~N})$ were found to be not statistically different from the baseline measurement. The peak transverse force measured in the chronic IMR animals was $4.6 \mathrm{~N}$ at $175 \mathrm{~mm} \mathrm{Hg}$ peak LVP. To determine whether directional differences exist, septal-lateral and transverse forces were compared at each level of peak LVP. No statistical differences were observed between these directions in the chronic IMR animals.

\section{Change in Force for Increasing Afterload: Control Versus Chronic IMR Animals}

To determine whether an inferior LV infarction results in a decrease in mitral annular forces, chronic IMR forces were compared with those measured previously in a healthy ovine model. ${ }^{15}$ Among all animals, the mean change in septal-lateral force was found to differ statistically between increasing levels of afterload $(P<.001)$ and animal groups $(P<.001)$. Septal-lateral forces in the control animals were found to be significantly larger than those in the chronic IMR group at $90 \mathrm{~mm} \mathrm{Hg}(P<.01), 125 \mathrm{~mm} \mathrm{Hg}(P<$ $.005), 150 \mathrm{~mm} \mathrm{Hg}(P<.005), 175 \mathrm{~mm} \mathrm{Hg}(P<.005)$, and $200 \mathrm{~mm} \mathrm{Hg}(P<.005)$. These results are plotted in Figure 3.

Among all animals, the mean change in transverse force was found to differ statistically between increasing levels of afterload $(P<.001)$ but not between animal groups. Although nonsignificant, the mean transverse forces in the chronic IMR group were observed to be consistently lower in magnitude than those measured in control animals, as shown in Figure 3.

\section{Rate of Change of Force During Isovolumetric Contraction: Control Versus Chronic IMR Animals}

The peak rate increase of force during isovolumetric contraction was quantified for both the control and chronic IMR animals at elevated levels of LVP. Among all animals, septal-lateral $\mathrm{dF} / \mathrm{dt}$ was found to differ significantly between increasing levels of peak $\operatorname{LVP}(P<.005)$ and animal groups $(P<.05)$. Within the control group, septal-lateral $\mathrm{dF} / \mathrm{dt}$ was found to increase significantly from the baseline condition

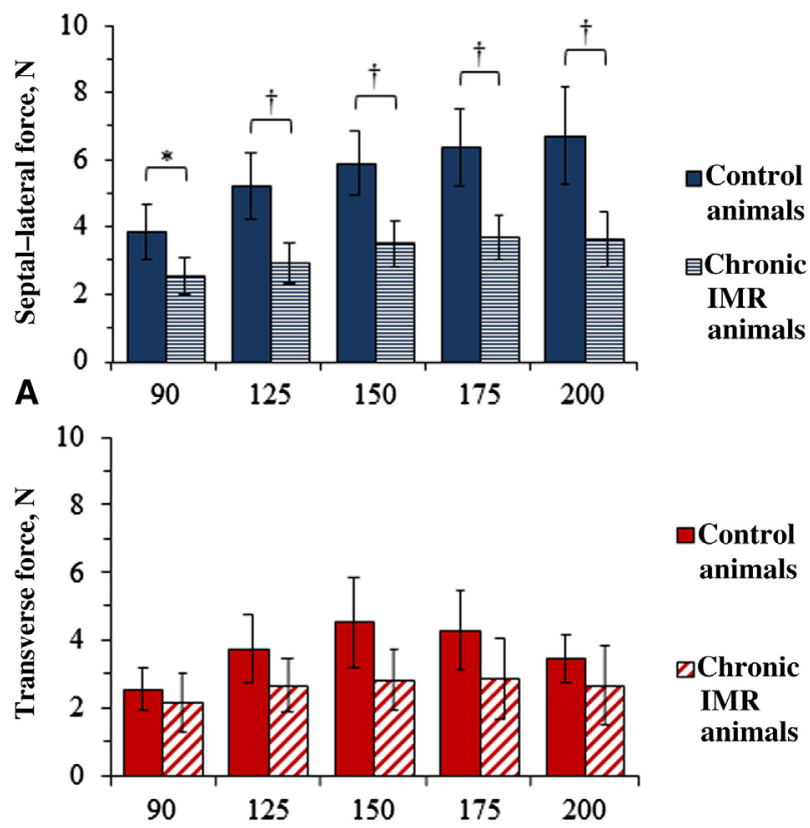

$B \quad$ Peak left ventricular pressure, $\mathbf{m m ~ H g}$

FIGURE 3. (A) The measured change in septal-lateral force throughout the cardiac cycle was observed to to be significantly greater in the control animals at each level of peak left ventricular pressure. (B) No significant differences in the change in transverse force throughout the cardiac cycle was observed between the animal groups and left ventricular pressure levels. $I M R$, Ischemic mitral regurgitation. ${ }^{*} P<.01 . \dagger P<.005$.

to $150 \mathrm{~mm} \mathrm{Hg}(P<.01), 175 \mathrm{~mm} \mathrm{Hg}(P<.005)$, and 200 $\mathrm{mm} \mathrm{Hg}(P<.001$; Table 3$)$. No significant differences were observed between the baseline and $125 \mathrm{~mm} \mathrm{Hg}$. In the chronic IMR group, the peak septal-lateral $\mathrm{dF} / \mathrm{dt}$ was found to increase significantly from the baseline to 150 $\mathrm{mm} \mathrm{Hg}(P<.005), 175 \mathrm{~mm} \mathrm{Hg}(P<.001)$, and $200 \mathrm{~mm}$ $\mathrm{Hg}(P<.001)$. Similar to the control group, no significant differences were found between the baseline condition and $125 \mathrm{~mm} \mathrm{Hg}$ peak LVP. After adjusting for multiple

TABLE 3. Peak rate of change of septal-lateral and transverse forces during isovolumetric contraction for the control and chronic IMR animals

\begin{tabular}{lccccc}
\hline \multirow{2}{*}{$\begin{array}{c}\text { Force direction and } \\
\text { animal group }\end{array}$} & $\mathbf{9 0}$ & $\mathbf{1 2 5}$ & $\mathbf{1 5 0}$ & $\mathbf{1 7 5}$ & $\mathbf{2 0 0}$ \\
\cline { 2 - 6 } $\begin{array}{l}\text { Septal-lateral } \\
\mathrm{dF} / \mathrm{dt}, \mathrm{N} / \mathrm{sec}\end{array}$ & & & & & \\
Control & $77 \pm 31$ & $126 \pm 48$ & $150 \pm 72 *$ & $169 \pm 89 \dagger$ & $180 \pm 95 \ddagger$ \\
Chronic IMR & $39 \pm 12$ & $42 \pm 6$ & $64 \pm 9 \dagger$ & $66 \pm 7 \ddagger$ & $74 \pm 12 \ddagger$ \\
Transverse & & & & & \\
$\quad \mathrm{dF} / \mathrm{dt}, \mathrm{N} / \mathrm{sec}$ & & & & & \\
Control & $36 \pm 16$ & $70 \pm 32$ & $88 \pm 42 \dagger$ & $85 \pm 43 *$ & $72 \pm 48$ \\
Chronic IMR & $30 \pm 18$ & $40 \pm 19$ & $60 \pm 17 \dagger$ & $68 \pm 35 \ddagger$ & $62 \pm 26 \dagger$ \\
\hline $\begin{array}{l}d F / d t, \text { Peak rate of change of force; } I M R, \text { ischemic mitral regurgitation. Signficance is } \\
\text { reported for the baseline values at } 90 \mathrm{~mm} \text { Hg peak left ventricular pressure in each } \\
\text { group and direction. } * P<.01 . \dagger P<.005 . \ddagger P<.001 .\end{array}$
\end{tabular}


comparisons, no significant differences in septal-lateral dF/ $\mathrm{dt}$ were found between the control and chronic IMR animal groups at each level of LVP.

In the transverse direction, the peak $\mathrm{dF} / \mathrm{dt}$ was found to increase significantly with afterload in all animals $(P<$ .001 ), but did not differ significantly between groups (Table 3). In the control group, transverse $\mathrm{dF} / \mathrm{dt}$ was found to increase significantly from the baseline to 150 $\mathrm{mm} \mathrm{Hg}(P<.005)$ and $175 \mathrm{~mm} \mathrm{Hg}(P<.01)$. In the chronic IMR animals, transverse $\mathrm{dF} / \mathrm{dt}$ was found to increase from the baseline to a peak LVP of $150 \mathrm{~mm} \mathrm{Hg}(P<.005)$, $175 \mathrm{~mm} \mathrm{Hg}(P<.001)$, and $200 \mathrm{~mm} \mathrm{Hg}(P<.005)$.

\section{DISCUSSION}

Ejection of the heart's blood to the systemic circulation requires the left ventricle to generate enough pressure to open the aortic valve leaflets and empty the LV volume. This critical function is accomplished by the myocardium aligned helically in the LV wall. During ventricular systole, the myocardium contracts and reduces the LV diameter by generating forces that act along the direction of each myocardial fiber. These forces not only facilitate the generation of LVP, but at the basal level, reduce the mitral annular area and compress devices implanted to the mitral annulus. ${ }^{14,15}$ The septal-lateral and transverse forces measured in this study are vector components of the circumferentially generated myocardial forces.

This study shows that an inferior LV infarction decreases significantly septal-lateral forces while decreasing modestly those in the transverse direction. This can be explained in that an inferior infarction not only impairs the ability of the infarcted myocardium to contract, but also alters the crosssectional geometry of the left ventricle. ${ }^{16,18-21}$ As a result of the infarction, the magnitudes of circumferentially directed forces in the posteroinferior wall are reduced and are more oblique directionally with respect to the geometric center of the left ventricle. As a result, the relative contributions of the posteroinferior myocardium to the radially directed septallateral and transverse forces are reduced. We believe the septal-lateral force was decreased to a greater extent because of ligation of the obtuse marginal 3 coronary artery, which has been shown previously to impair more of the posterior wall. $^{20}$

Lower observed forces in the chronic IMR animals have important implications in the development of minimally invasive and transcatheter IMR devices. These forces can inform bench and computational tests to evaluate the structural durability and relevant failure modes of these devices. International standards organization standards and U.S. Food and Drug Administration (FDA) guidelines recommend evaluating these devices under cyclic forces at magnitudes at least as severe as those anticipated in vivo. ${ }^{22,23}$ Although septal-lateral and transverse forces were observed to be reduced in the presence of IMR, a reasonable safety margin needs to be maintained to ensure device durability and patient safety. ${ }^{5,6,24}$

Previous findings in healthy animals demonstrated directional differences in the change in force throughout the cardiac cycle. ${ }^{15}$ These differences and their exacerbation with increasing LVP can inform the structural strengthening of devices and worst-case loading conditions. Despite these previous findings, directional differences were not observed in the chronic IMR animals. An inferior infarction was found to decrease significantly the septal-lateral forces, but not to a magnitude that was different statistically from those measured in the transverse direction. Although transverse forces were consistently lower in the chronic IMR group, they were not different statistically from transverse forces measured in healthy animals.

In addition to cyclic force magnitudes, the rates at which these forces increase during ventricular contraction carry equal importance. These rates can inform more accurately device testing and the use of device materials (eg, polymers) with rate-dependent behavior. ${ }^{22-24}$ This study was the first to quantify these rates at elevated levels of peak LVP. The rates measured were found to increase significantly with peak LVP, but did not differ significantly between directions and groups. Although statistically significant differences in $\mathrm{dF} /$ dt were not observed between groups in the septal-lateral direction, we believe the large differences in magnitude are representative of a meaningful difference that might be observed to be statistically significant with a larger sample size. When combined with the peak magnitudes of these cyclic forces, measured rates will contribute to more accurate experimental and computational models that assist further in optimizing device materials, design, durability, and safety.

The translation of the measured chronic IMR annular forces in the ovine model to what may be anticipated in patients with IMR requires careful attention. Healthy ovine animals and humans have been compared previously and were shown to have similar mitral annular areas, LV mass and wall thickness, and comparable LVP and $\mathrm{d}(\mathrm{LVP}) / \mathrm{dt}^{3,15}$ Ligation of the obtuse marginal coronaries infarcts approximately $20 \%$ of the LV mass, includes the posteromedial papillary muscle, and produces increasingly more severe MR with progressive LV remodeling. ${ }^{16,18-20}$ Similar to clinical descriptions, abnormalities and reductions in both LV and mitral valve contractility are observed with significant increases in end systolic and diastolic LV volumes. ${ }^{16,25,26}$ Although the size and age of infarcts in patients with IMR vary widely, LV wall motion abnormalities are overwhelmingly located in the posteroinferior aspect of the left ventricle and usually involve the posterior papillary muscle. ${ }^{21}$

Given that our forces were measured under anesthesia and in the postcardioplegic heart, we believe mitral annular forces in humans with a posterior infarct to be of greater 
magnitude than the forces we report at $125 \mathrm{~mm} \mathrm{Hg}$ peak LVP. The forces expected in the human mitral annulus may present greater directional heterogeneity because coronary disease may be more widespread and may affect global LV contraction. We hypothesize a greater degree of localized myocardial infarction may result in a disproportionate systolic annular area reduction and potential shearing of devices in the mitral annulus. Moreover, annular undersizing, as seen in restrictive mitral annuloplasty, may differ from the results we present because the ring is likely to undergo cyclic tension from a contracting and grossly dilated left ventricle. Future studies are required to describe these force profiles and to understand the potential heterogeneity introduced by reshaping the mitral annulus to a given device.

\section{Limitations}

Several limitations exist in the methods and results of this study. Limitations resulting from device annular sizing, calibration, and limits of reporting absolute forces have been described previously. ${ }^{15}$ In addition to these, the magnitude of forces measured in the chronic IMR model is likely dependent on infarct size and may change with a lesser or greater degree of myocardial infarction. Described forces are limited to this IMR model and may not represent the forces that may be seen in other mitral etiologies. Because IMR repairs aim to reshape and reduce mitral annular area, transducers implanted in our chronic IMR animals were sized to the enlarged mitral annulus. This was done to reduce any unknown effects of transducer-annular sizing on measured forces. In each study, the transducers were found to be either slightly undersized or exhibit a snug but not oversized fit. Absolute forces experienced by each device resulting from implantation and function were difficult to quantify because of the observed variations in the diastolic forces from combined changes in annular contractility. For these reasons, the change in force throughout the cardiac cycle is reported.

Because implantation of any device likely alters native mitral annular mechanics, any forces measured may not be equal to those in absence of the implanted device. Although the areal reduction of the mitral annulus and myocardial strain can be measured noninvasively, the relationship between these quantities and annular force is unknown. For these reasons, mitral annular forces must be measured currently with an implanted device. Because all studies were terminal, the long-term impact of these devices on left heart function was not assessed.

\section{CONCLUSIONS}

Mitral annular forces were measured for the first time in a chronic IMR animal model. Our findings demonstrate an inferior LV infarct to result in significantly decreasing septal-lateral forces while lowering modestly those in the transverse. The rate of change of septal-lateral and transverse forces during isovolumetric contraction were also quantified and shown to increase significantly with peak LVP. Using similar methods, parallel studies are currently underway to evaluate repair techniques that reduce forces acting on devices as well as those contributing to a tethering subvalvular mitral valve geometry. Combined, these force measurements will aid significantly in the development of devices interacting with the mitral annulus, including those implanted through minimally invasive and percutaneous approaches.

We acknowledge the contributions to and development of the data acquisition platform provided by members of the Cardiovascular Research Unit in Århus, Denmark.

\section{References}

1. Braun J, van de Veire NR, Klautz RJM, Versteegh MI, Holman ER, Westenberg JJ, et al. Restrictive mitral annuloplasty cures ischemic mitral regurgitation and heart failure. Ann Thorac Surg. 2008;85:430-7.

2. Bolling SF, Pagani FD, Deeb GM, Bach DS. Intermediate-term outcome of mitral reconstruction in cardiomyopathy. J Thorac Cardiovasc Surg. 1998;115: 381-6.

3. Carpentier A, Adams DH, Filsoufi F. Carpentier's reconstructive valve surgery: from valve analysis to valve reconstruction. Maryland Heights, Mo: Saunders 2010 .

4. Mirabel M, Lung B, Baron G, Messika-Zeitoun D, Detaint D, Vanoverschelde JL et al. What are the characteristics of patients with severe, symptomatic, mitral regurgitation who are denied surgery? Eur Heart J. 2007;28:1358-85.

5. Piazza N, Asgar A, Ibrahim R, Bonan R. Transcatheter mitral and pulmonary valve therapy. J Am Coll Cardiol. 2009;53:1837-51.

6. Mack MJ. Percutaneous treatment of mitral regurgitation: so near, yet so far! $J$ Thorac Cardiovasc Surg. 2008;135:237-9.

7. Chiam PTL, Ruiz CE. Percutaneous transcatheter mitral valve repair: a classification of the technology. J Am Coll Cardiol Int. 2011;4:1-13.

8. Webb JG, Wood DA, Ye J, Gurvitch R, Masson JB, Rodes-Cabau J, et al. Transcatheter valve-in-valve implantation for failed bioprosthetic heart valves. Circulation. 2010;121:1848-57.

9. Lam Y, Lee P, Yong G, Yan BP. Investigational devices for mitral regurgitation: state of the art. Expert Rev Med Devices. 2011;8:105-14.

10. Hasenkam JM, Nygaard H, Paulsen PK, Kim WY, Hansen OK. What force can the myocardium generate on a prosthetic mitral valve ring? An animal experimental study. J Heart Valve Dis. 1994;3:324-9.

11. Shandas R, Mitchell M, Conrad C, Knudson O, Sorrell J, Mahalingam S, et al. A general method for estimating deformation and forces imposed in vivo on bioprosthetic heart valves with flexible annuli: in vitro and animal validation studies. J Heart Valve Dis. 2001;10:495-504.

12. Jensen MO, Jensen H, Smerup M, Levine RA, Yoganathan AP, Nygaard H, et al. Saddle-shaped mitral valve annuloplasty rings experience lower forces compared with flat rings. Circulation. 2008;118:S250-5.

13. Jensen MO, Jensen H, Nielsen SL, Smerup M, Johansen P, Yoganathan AP, et al. What forces act on a flat rigid mitral annuloplasty ring? J Heart Valve Dis. 2008; 17:267-75.

14. Siefert AW, Jimenez JH, West S, Koomalsingh KJ, Gorman RC, Gorman JH III et al. In vivo transducer to measure mitral annular forces. J Biomech. 2012;45 1514-6.

15. Siefert AW, Jimenez JH, Koomalsingh KJ, West DS, Aguel F, Shuto T, et al. Dynamic assessment of mitral annular force profile in an ovine model. Ann Thorac Surg. 2012;94:58-64.

16. Gorman JH III, Gorman RC, Jackson BM, Enomoto Y, St. John-Sutton MG, Edmunds LH Jr. Annuloplasty ring selection for chronic ischemic mitral regurgitation: lessons from the ovine model. Ann Thorac Surg. 2003;76 1556-63.

17. National Research Council of the National Academies. Guide for the care and use of laboratory animals. National Institutes of Health Publication 85-23. Rev. 1996. Bethesda, Md: National Institutes of Health. 
18. Edmunds LH Jr, Gorman JH III, Gorman RC. Sheep models of postinfarction left ventricular remodeling. In: Singal PK, Dixon IMC, Kirsenbaum LA, Dhalla NS, eds. Cardiac remodeling and failure. Boston, Mass: Kluwer Academic Publishers; 2003:232-44.

19. Gorman JH III, Gorman RC, Plappert T, Jackson BM, Hiramatsu Y, St JohnSutton MG, et al. Infarct size and location determine development of mitral regurgitation in the sheep model. J Thorac Cardiovasc Surg. 1998;115:615-22.

20. Llanera MR, Nance ML, Streicher JT, Lima JA, Savino JS, Bogen DK, et al. Large animal model of ischemic mitral regurgitation. Ann Thorac Surg. 1994; 57:432-9.

21. Gorman RC, Gorman JH III, Edmunds LH Jr. Ischemic mitral regurgitation. In: Cohn LH, Edmunds LH Jr, eds. Cardiac surgery in the adult. New York: McGraw-Hill; 2003:751-69.

22. Food and Drug Administration. Draft guidance for industry and FDA staff: heart valves: investigational device exemption (IDE) and premarket approval (PMA) applications. Rockville, MD: National Press Office. Submitted for Comment, January 20, 2010.

23. International Standards Organization. Draft international standard ISO 5840-3, cardiovascular implants: cardiac valve prostheses: part 3: heart valve substitutes implanted by minimally invasive techniques, 2011. Geneva, Switzerland.

24. Aguel F, Hillebrenner M, Stewart SF, Swain J, Hampshire V, Zuckerman B. U.S. regulatory considerations for heart valve implantation by minimally invasive surgery. Cardio Eng Tech. 2011;2:62-5.

25. Guy TS IV, Moainie SL, Gorman JH III, Jackson BM, Plappert T, Enomoto Y, et al. Prevention of ischemic mitral regurgitation does not influence the outcome of remodeling after posterolateral myocardial infarction. J Am Coll Cardiol. 2004;43:377-83.

26. Yiu SF, Enriquez-Serano M, Tribouilloy, Seward JB, Tajik AJ. Determinants of the degree of functional mitral regurgitation in patients with systolic left ventricular dysfunction. Circulation. 2000;102:1400-6. 